\title{
Research of urban rail driver's workload based on questionnaire and
}

\section{simulation}

\author{
Li Lan-peng ${ }^{1, a}$, Huang Yuan-chun ${ }^{2, b}$, Yuan Shu-qing ${ }^{3, c}$ \\ 1, 2, 3 School of Urban Rail Transportation, Shanghai University of Engineering Science, \\ Shanghai, China

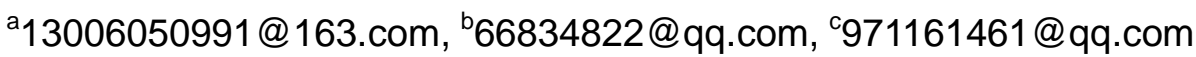

Keywords: Pressure Load; Psychological and Physiological Monitoring System; Questionnaire Survey

\begin{abstract}
To study the workload as well as the psychological and physiological characteristics of urban rail train drivers, the authors track and evaluate the drivers' work stress and the related critical influences using a questionnaire and statistical analysis. The results show that the main sources of stress include workload, equipment failures, management style, and the driver's gender, age, and years of service. Meanwhile, simulated driving tests and the Spirit Bio-feedback Instrument (an advanced psychological and physiological parameters monitoring system) are used to investigate changes of the related parameters during the driving operation. The study finds that during different working conditions there are statistical differences of the parameters such as electrocardiogram, brain activity and galvanic skin. Based on the above researches, an Urban Rail Train Driver Workload and Work Stress Model is developed.
\end{abstract}

\section{Introduction}

With the expanding of city scale, as well as the saturation of ground traffic, urban rail transit as the main channel for cities to ease traffic pressure and got rapid development. Operating safety is the prerequisite and guarantee for urban rail system to achieve smooth and efficient operation[1]. Although the improvement of degree of urban rail transit operation automation has never stopped, the driver does have a significant impact on that. On the one hand, among with significant safety responsibility, a single, boring, even dark work environment, and a strict and high standard of work system is easy to induce the driver's psychological stress[2]; On the other hand the shift system cause biological rhythm disturbance, long time for forced postures also easy to cause the driver's physiological fatigue. The combination of psychological stress and physical fatigue can easily lead to the overweight professional pressure, affect the driver's working condition, finally cause terrible accidents, So, it's necessary to find out those key stress factors, put forward measures to slow or reduce the occupational stress of drivers, and that make great significance to keeping operational safety.

The current research relies on simulation driving condition built by simulation driving device, then we record the drivers' physiology changes in the whole process of driving in the simulation environment, finally by means of questionnaire survey, we can get bigger and greater impact occupational stress factors which under the control of operation company with the effective intervention level and use for setting up the drivers' workload model. The work after statistics is discussing the structure of the occupational stress factors, and analyzes the occupational stress 
factors' influence and the relationship with different individual characteristics of the drivers. Eventually, targeted countermeasures will be made out to ease or reduce occupational stress and ensure that the drivers with good working condition to keep the operation safety of the urban rail.

\section{Method}

\section{The research review}

Since the "Father of the pressure " Selye, in 1956, applied the pressure to scientific research [3], the Institute of Sociology of the Michigan University, in 1962, started pressure study and proposed working pressure mode ISR (Institute for Social Research Model). Then research about work pressure began to attract researchers' attention. Recently, Fried and Shirom (2008) [4] and others analyzed 113 independent samples, which published and unpublished studies in the past 25 years, separately using structural equation model and an alternative model analysis the relationship among with work pressure, psychological adjustment, work performance and turnover, identify the theoretically factors that influence the pressure behavior .

Looked from the historical literature, the research of work pressure and its model has achieved fruitful results and in the studies of model of work pressure as well as its mechanism of action have also been relatively mature. But from research achievements that ever made, it is difficult to find any targeted and obvious research paper about urban rail drivers' work pressure who are regarded as the special occupational groups. There are few researches about the urban rail drivers, workload model.

So far, Chinese scholars applied data investigation and analysis to building the Chinese railway locomotive drivers' work pressure scale list, and found that Chinese railway locomotive driver's work pressure mainly comes from work environment, workload, organization and management, management behavior, career development, interpersonal relationship, etc. [5]. Some researchers have managed to obtain work stress scale list based on typical pressure model through investigation of Taiwan railway drivers to found that the physical environment and route situation are the main sources of the railway driver's work stress [6].

\section{Stress factors}

Based on these studies above, and through interviews with drivers and experts on the urban rail train driving job content and requirements to find driving operation and the organizational management became two major sources of occupational stress that affect a driver, so tease out specific stress factors of the two sources that contains in reality. Finally we design specific stress factors questionnaire in base of these 13 stress factors entries which focused on the investigation of each driver's perception and feeling frequency of the stress factors. 
Table 1 Stress sources \& Stress factors

\begin{tabular}{lll}
\hline sources & & \multicolumn{1}{c}{ factors } \\
\hline & A1 Fear into the dark tunnel; \\
& A2 $\quad$ Blurred vision because of some reasons like \\
& weather; \\
& A3 Worry about emergency like conflict between \\
& passengers and train; \\
& A4 Face train and signal malfunctions; \\
& A5 Small enclosed cab; \\
& A6 Unbearable traffic noise; \\
& A7 $\quad$ Uncomfortable seat; \\
& A8 Little rest time between breaks; \\
& A9 Be ill during driving; \\
& B1 Take part in vocational training and evaluation; \\
& B2 Management style of leadership; \\
& B3 Few development opportunity for career; \\
& B4 Low level of autonomy;
\end{tabular}

\section{Reliability Testing}

Reliability

Using the SPSS reliability test to analyze the questionnaire data[8]. Selecting the Cronbach's alpha $(\alpha)$ homogeneity reliability coefficient method to test the consistency of the questionnaire. Data of alpha coefficient more close to 1, the higher reliability, and the $\alpha$ coefficient should be greater than 0.7 so that can meet the reliability requirements. Test results are as follow:

Table 2 Reliability statistics

\begin{tabular}{ccc}
\hline Cronbach's Alpha(Raw reliability) & Normalized Cronbach's Alpha & Number of items \\
\hline .903 & .903 & 13 \\
\hline
\end{tabular}

As we can see from the table that normalized reliability is 0.903 and reaches a very ideal reliable level.

\section{Validity}

Making a validity test through the SPSS to get Bartlett sphericy test and KMO (Kaiser Meyer Olkin) test data, Test results are as follow:

Table 3 KMO \& Bartlett test

\begin{tabular}{lc}
\hline $\begin{array}{c}\text { Numbers enough for Kaiser-Meyer-Olkin test } \\
\text { Bartlett sphericy test } \quad \text { Approximate chi-square } \\
\text { Sig. }\end{array}$ & 905 \\
\hline As we can see from the table that the Significant difference(Sig) of Bartlett sphericy test is \\
0. $000(<0.001)$, which shows the difference is significant; The KMO test data is 0.823 close to 1 , \\
also regarded ideal level. The results show the validity of questionnaire with a good level.
\end{tabular}




\section{Participants}

A total of 300 participants who are the on-the-job drivers were selected randomly from Shanghai metro company, and the valid response rate is 98.7\% (296 of 300 are effective questionnaires). Table 4 shows the participants' detail statistic information.

Table 4 Participants' basic information

\begin{tabular}{|c|c|c|c|c|c|c|c|c|c|}
\hline $\begin{array}{c}\text { Individual } \\
\text { characteristics }\end{array}$ & \multicolumn{2}{|r|}{ Gender } & \multicolumn{3}{|c|}{ Age } & \multirow[b]{2}{*}{$>=31$} & \multicolumn{3}{|c|}{ Working years } \\
\hline Classification & Male & Female & $<=25$ & \multicolumn{2}{|l|}{$26 \sim 30$} & & $<=3$ & $4 \sim 7$ & $>=8$ \\
\hline Number of samples & 280 & 16 & 44 & \multicolumn{2}{|l|}{205} & 47 & 139 & 98 & 59 \\
\hline proportion & $94.6 \%$ & $5.4 \%$ & $14.9 \%$ & $69.2 \%$ & & $15.9 \%$ & $47.0 \%$ & $33.0 \%$ & $20.0 \%$ \\
\hline $\begin{array}{c}\text { Individual } \\
\text { characteristics }\end{array}$ & \multicolumn{4}{|c|}{ Technology level } & & \multicolumn{4}{|c|}{ Degree } \\
\hline Classification & Primary & Intermediate & Senior & Technician & $\begin{array}{c}\text { No } \\
\text { level }\end{array}$ & Unc & rraduate & collage & Secondary school \\
\hline $\begin{array}{c}\text { Number of } \\
\text { samples }\end{array}$ & 57 & 64 & 170 & 1 & 4 & & 74 & 213 & 9 \\
\hline proportion & $19.3 \%$ & $21.6 \%$ & $57.4 \%$ & $0.3 \%$ & $1.4 \%$ & & $5 \%$ & $72 \%$ & $3 \%$ \\
\hline
\end{tabular}

\section{Analysis Design}

First, the analysis of survey data using a pressure matrix method [6] based on each of the respective pressure that measured by the frequency and extent of the feelings to get influence of various stress factors, and divided it into four grades. The most severe stress grade is four, severity rating descending successively, and the lightest stress grade is one grade. Stress matrix table is as follow:

Table 5 Stress matrix table

$\begin{array}{cccccc}\text { Much } & \text { Grade } & \text { Some } & \text { Less pressure } & \text { No pressure } \\ \text { pressure } & \text { pressure } & & 2 & 1 \\ \text { always } & 4 & 4 & 3 & 2 & 1 \\ \text { often } & 4 & 4 & 3 & 2 & 1 \\ \text { sometimes } & 3 & 3 & 3 & 2 & 1 \\ \text { occasionally } & 2 & 2 & 2 & 1 & 1 \\ \text { never } & 1 & 1 & 1 & \end{array}$

Afterwards, the one to four pressure weight (hereinafter represented by w) were set to $1,2,3,4$, namely $\mathrm{w} 1=1, \mathrm{w} 2=2, \mathrm{w} 3=3, \mathrm{w} 4=4$. The average weight of each pressure obtained by questionnaire statistical weight, then convert to stress level of severity in all the pressure terms.

In addition, in order to further understand the relationship between the driver's individual characteristics and stress factors, we analyze the correlation between stress factors and aspects of individual characteristics like gender, age, working years, qualifications and technical level and others. By using SPSS analysis software, we make an independent samples T-test for gender [7]; besides, for age, working years, qualifications and technical level using analysis of variance [7], and compare the average differences between pairs later[7], we eventually have known the which pairs reach significant level. 


\section{Results}

\section{Analysis for stress factors influence}

Stress factors can cause influence of different level. Our research gives the rank by using pressure matrix method [6].

Table 6 Calculation of w by pressure matrix method

\begin{tabular}{cccccccccccccc}
\hline $\begin{array}{c}\text { Stress } \\
\text { factors }\end{array}$ & A1 & A2 & A3 & A4 & A5 & A6 & A7 & A8 & A9 & B1 & B2 & B3 & B4 \\
\hline w & 1.83 & 2.15 & 2.13 & 2.29 & 1.74 & 2.04 & 2.14 & 2.20 & 2.16 & 2.05 & 2.34 & 1.88 & 1.89 \\
Average & & & & & & & 2.07 & & & & & & \\
\hline
\end{tabular}

The rank of Stress factors' influence (Table 7) is based on the Table 6, detail ranks of each stress factors are as follow:

Table 7 The rank of Stress factors' influence (from high to low)

\begin{tabular}{ll}
\hline & \multicolumn{1}{c}{ The rank of Stress factors' influence } \\
\hline B2 & Management style of leadership; \\
A4 & Face train and signal malfunctions; \\
A8 & Little rest time between breaks; \\
A9 & Be ill during driving; \\
A2 & Blurred vision because of some reasons like weather; \\
A7 & Uncomfortable seat; \\
A3 & Worry about emergency like conflict between passengers and train; \\
B1 & Take part in vocational training and evaluation; \\
A6 & Unbearable traffic noise; \\
B4 & Low level of autonomy; \\
B3 & Few development opportunity for career; \\
A1 & Fear into the dark tunnel; \\
A5 & Small enclosed cab; \\
\hline
\end{tabular}

The above table shows that the current driver feel more significant pressure mainly comes from working load, equipment malfunctions and management ways. In terms of working load, the urban rail driver's job requires drivers to continue to maintain the spirit of highly concentrated, and can take only sitting posture in a closed and narrow space, eyes must keep looking ahead, long-term forced posture and monotonous driving conditions easily to generate driving fatigue, as well as feeling the heavy working load pressure. Especially, drivers' health status is a important stress factor, in fact, it is unscientific to force a subway driver to finish their a series of duty tasks. In terms of equipment, train and signal malfunctions is also the most prone to accidents. In according to Shanghai metro company's shift system, it asks the drivers to master a variety of train models of operation skills and resolve malfunctions in emergency situations even if single driver on duty. Therefore, equipment malfunctions and other emergencies will push more pressure on the driver. For the "Management style of leadership", may due to Chinese special State-owned enterprises condition combined with state-owned enterprises system, the leadership has the absolute power to make an order commonly so that employees have opinions but no anger, thus accumulating great 
pressure.

\section{The relativity analysis for gender}

Existing research shows that affected by thinking, traditions, institutions, and many other factors, women are more likely to feel the heavier occupational stress [8]. Since the independent variable, gender, is dichotomous variable, the dependent variable is a continuous variable, so this paper using SPSS software through independent sample T-test, 95\% confidence interval chosen to give the higher average numbers of female drivers on the A9 and B2 stress factors than men drivers (A9: Mean $_{\text {male }}=3.50>\mathrm{Mean}_{\text {female }}=2.15 ; \mathrm{B} 2: \mathrm{Mean}_{\text {male }}=3.75>\mathrm{Mean}_{\mathrm{female}}=2.33$ ) and with significant differences $\left(\mathrm{P}_{\mathrm{A} 9}=0.003<0.05 ; \mathrm{P}_{\mathrm{B} 2}=0.008<0.05\right)$, namely, female is more sensitive. This may be due to physiological and psychological differences between men and women, such as women in the physiological period during physical discomfort will affect its work on duty; To the more exquisite female psyche, the management styles of the competent leadership such as excessive criticism are more prone to stress.

Table 8 T- test of the relativity analysis --- gender

\begin{tabular}{ccccccc}
\hline Test variables & gender & $\mathrm{N}$ & average & $\begin{array}{c}\text { Standard } \\
\text { deviation }\end{array}$ & $\mathrm{T}$ & $\begin{array}{c}\text { Significance } \\
(\mathrm{P})\end{array}$ \\
\hline \multirow{2}{*}{ A9 Be ill during driving } & & & & .889 & -3.020 & 0.003 \\
B2 Management style of leadership & male & 280 & 2.15 & & & \\
& female & 16 & 3.50 & 0.577 & & 0.008 \\
& female & 16 & 3.75 & 0.500 & & \\
\hline
\end{tabular}

${ }^{*} \mathrm{p}<.05,{ }^{* *} \mathrm{p}<.01,{ }^{* * *} \mathrm{p}<.001$

\section{The relativity analysis for degree}

A survey ever showed that, due to the highly educated employees' weighty responsibilities, heavy mental workload and other reasons, resulting in high-degree workers feeling more occupational stress than the low-educated workers [9]. There is another survey shows, facing different pressure sources, that education situation behaves positively correlated or negatively correlated are both possible[10]. Because the independent variable, degree, is categorical variables in most case, the dependent variable is a continuous variable, therefore, the research's analysis using SPSS software and ANOVA test to find out drivers' different education situation have no significant differences with stress factors.

Table 9 Analysis of variance of significance --- degree

\begin{tabular}{ccc}
\hline & Stress factor & Significance (P) \\
\hline A2 & Blurred vision because of some reasons like weather & 0.032 \\
\hline
\end{tabular}

Further using the Scheffe multiple comparison method, which uses pairwise comparison, get an undergraduate degree perception data of the driver's pressure on the A2 factor is higher than college degree and reached significant levels $(\mathrm{P}<0.05)$, while the technical secondary school degree of drivers because of less number of the drivers showed no statistical difference. Drivers with undergraduate degree preserve the sense of responsibility intensively and more strict self-behave to away from mistakes can be regarded as a feasible reason, so they are more sensitive to impact of external factors and will feel more pressure. 
Table 10 Multiple comparison of Scheffe method --- degree

\begin{tabular}{|c|c|c|c|c|c|c|c|}
\hline \multirow[t]{2}{*}{$\begin{array}{l}\text { Dependent } \\
\text { variable }\end{array}$} & \multirow[t]{2}{*}{ (I) degree } & \multirow[t]{2}{*}{ (J) degree } & \multirow{2}{*}{$\begin{array}{c}\text { Average } \\
\text { difference } \\
\text { (I-J) }\end{array}$} & \multirow[t]{2}{*}{$\begin{array}{l}\text { Standard } \\
\text { error(SE) }\end{array}$} & \multirow[t]{2}{*}{$\begin{array}{l}\text { Signific } \\
\text { ance }(P)\end{array}$} & \multicolumn{2}{|c|}{$\begin{array}{c}95 \% \text { confidence } \\
\text { interval }\end{array}$} \\
\hline & & & & & & $\begin{array}{l}\text { Lower } \\
\text { bound }\end{array}$ & $\begin{array}{l}\text { Upper } \\
\text { bound }\end{array}$ \\
\hline & & $\begin{array}{l}\text { Secondary } \\
\text { school }\end{array}$ & -.66250 & .39744 & .258 & $\begin{array}{c}-1.664 \\
0\end{array}$ & .3390 \\
\hline $\begin{array}{l}\text { A2 Blurred } \\
\text { vision }\end{array}$ & Collage & Undergraduate & $-.61806^{*}$ & .24350 & .048 & $\begin{array}{c}-1.231 \\
7\end{array}$ & -.0044 \\
\hline $\begin{array}{c}\text { because of } \\
\text { some }\end{array}$ & Undergrad & $\begin{array}{l}\text { Secondary } \\
\text { school }\end{array}$ & -.04444 & .41781 & .994 & $\begin{array}{c}-1.097 \\
3\end{array}$ & 1.0084 \\
\hline $\begin{array}{c}\text { reasons } \\
\text { like } \\
\text { weather }\end{array}$ & uate & Collage & $.61806^{*}$ & .24350 & .048 & .0044 & 1.2317 \\
\hline
\end{tabular}

\section{The relativity analysis for age}

The existing studies show that occupational stress sources of different ages facing are different. Generally the younger age groups feel a sense of crisis, the most severe level of occupational stress, the older groups endure higher workload [11] [12]. Because the independent variable, age, is categorical variable in common, dependent variable as continuous variable, the current research using analysis of variance of different ages then found A2, A5, B2 and B3 factors were significantly different feeling pressure, theirs significance probability $\mathrm{P}$ were less than 0.05 , the others factors didn't reach such extremely difference level.

Table 11 Analysis of variance of significance --- age

\begin{tabular}{llcc}
\hline & \multicolumn{1}{c}{ Stress factors } & Levene statistics & Significance \\
\hline A2 & Blurred vision because of some reasons like weather & 3.277 & .040 \\
A5 & Small enclosed cab & 3.421 & .035 \\
B2 & Management style of leadership & 3.090 & .048 \\
B3 & Few development opportunity for career & 4.131 & .018 \\
\hline
\end{tabular}

Approaching with the Scheffe multiple comparison method to find out the age group of "26 30 " on the pressure sensitivity level is significantly higher than group under the age of 25 . Stress factors above mainly focused on workload aspects, it shows that young drivers because of good physical fitness as well as short work time have the higher endurance on the work load and special environment, while the older drivers with physical quality declined slightly result from the long-term work under environmental pressure face the increasing pressure owing to accumulated over a long period. 
Table 12 Multiple comparison of Scheffe method --- age

\begin{tabular}{|c|c|c|c|c|c|c|c|}
\hline \multirow{2}{*}{$\begin{array}{c}\text { Dependent } \\
\text { variable }\end{array}$} & \multirow[b]{2}{*}{ (I) age } & \multirow[b]{2}{*}{$(\mathrm{J})$ age } & \multirow{2}{*}{$\begin{array}{c}\text { Mean } \\
\text { difference } \\
(\mathrm{I}-\mathrm{J})\end{array}$} & \multirow{2}{*}{$\begin{array}{l}\text { Standard } \\
\text { error(SE) }\end{array}$} & \multirow[b]{2}{*}{ Significance $(\mathrm{P})$} & \multicolumn{2}{|c|}{$95 \%$ confidence interval } \\
\hline & & & & & & Lower bound & Upper bound \\
\hline \multirow{3}{*}{$\mathrm{A} 2$} & $<=25$ & $26 \sim 30$ & .445 & .232 & .016 & -.13 & 1.02 \\
\hline & & $>=31$ & .015 & .290 & .999 & -.70 & .73 \\
\hline & $26 \sim 30$ & $<=25$ & -.445 & .232 & .016 & -1.02 & .13 \\
\hline \multirow{5}{*}{ A5 } & & $>=31$ & -.431 & .220 & .151 & -.97 & .11 \\
\hline & $<=25$ & $26 \sim 30$ & .494 & .218 & .008 & -.05 & 1.03 \\
\hline & & $>=31$ & .336 & .273 & .470 & -.34 & 1.01 \\
\hline & $26 \sim 30$ & $<=25$ & -.494 & .218 & .008 & -1.03 & .05 \\
\hline & & $>=31$ & -.158 & .207 & .749 & -.67 & .35 \\
\hline \multirow{3}{*}{ B2 } & $<=25$ & $26 \sim 30$ & .052 & .248 & .009 & -.56 & .67 \\
\hline & & $>=31$ & -.076 & .311 & .970 & -.84 & .69 \\
\hline & $26 \sim 30$ & $<=25$ & -.052 & .248 & .009 & -.67 & .56 \\
\hline \multirow{5}{*}{ B3 } & & $>=31$ & -.128 & .236 & .863 & -.71 & .45 \\
\hline & $<=25$ & $26 \sim 30$ & .247 & .241 & .005 & -.35 & .84 \\
\hline & & $>=31$ & -.075 & .302 & .970 & -.82 & .67 \\
\hline & $26 \sim 30$ & $<=25$ & -.247 & .241 & .005 & -.84 & .35 \\
\hline & & $>=31$ & -.322 & .229 & .375 & -.89 & .24 \\
\hline
\end{tabular}

\section{The relativity analysis for working years}

The working years variable is a categorical variable and the dependent variable is a continuous variable. We started an analysis of variance of significance of the SPSS analysis and found out that drivers with different working years had different significant correlation. Especially, they had obvious significance differences in the aspects of A8, A9 and B4. Those stress factors' significance probability $\mathrm{P}$ were lower than 0.05 .

Table 13 Analysis of variance of significance --- working years

\begin{tabular}{llcc}
\hline & \multicolumn{1}{c}{ Stress factors } & Levene statistics & Significance $(\mathrm{P})$ \\
\hline A8 & Little rest time between breaks & 3.424 & .035 \\
A9 & Be ill during driving & 4.271 & .016 \\
B4 & Low level of autonomy & 4.702 & .010 \\
\hline
\end{tabular}

To launch a further data analysis through Scheffe multiple comparison method in order to draw a conclusion that length of service for more than 8 years group's pressure sensitivity is significantly higher than working for 3 years or less time when facing the three factors above, the group of 4 7 working years had the same situation like " $<=3$ " years group. This suggests that along with the increase of length of service, the drivers feel that all kinds of work pressure, especially comes from the length of rest time during driving, body state and the standard operation of the equipment, are increasing. This may be due to the driver engaged in a single tedious work, resulting in mental fatigue, besides, stress accumulates gradually as the work time growing, and finally pressure on the standardization of job requirements appears. 
Table 14 Multiple comparison of Scheffe method --- working years

\begin{tabular}{|c|c|c|c|c|c|c|c|}
\hline \multirow[b]{2}{*}{$\begin{array}{c}\text { Dependent } \\
\text { variable } \\
\end{array}$} & \multirow[b]{2}{*}{$\begin{array}{c}\text { (I) working } \\
\text { years }\end{array}$} & \multirow[b]{2}{*}{$\begin{array}{c}(\mathrm{J}) \text { working } \\
\text { years }\end{array}$} & \multirow{2}{*}{$\begin{array}{c}\text { average } \\
\text { difference } \\
(\mathrm{I}-\mathrm{J}) \\
\end{array}$} & \multirow[b]{2}{*}{$\begin{array}{l}\text { Standard } \\
\text { error(SE) }\end{array}$} & \multirow[b]{2}{*}{$\begin{array}{c}\text { Significance } \\
(\mathrm{P})\end{array}$} & \multicolumn{2}{|c|}{$95 \%$ confidence interval } \\
\hline & & & & & & $\begin{array}{l}\text { Lower } \\
\text { bound }\end{array}$ & $\begin{array}{l}\text { Upper } \\
\text { bound }\end{array}$ \\
\hline \multirow{6}{*}{ A8 } & \multirow{2}{*}{$<=3$} & $4 \sim 7$ & -.390 & .181 & .010 & -.84 & .06 \\
\hline & & $>=8$ & -.277 & .214 & .043 & -.80 & .25 \\
\hline & \multirow[t]{2}{*}{$4 \sim 7$} & $<=3$ & .390 & .181 & .010 & -.06 & .84 \\
\hline & & $>=8$ & .114 & .226 & .008 & -.45 & .67 \\
\hline & \multirow[t]{2}{*}{$>=8$} & $<=3$ & .277 & .214 & .043 & -.25 & .80 \\
\hline & & $4 \sim 7$ & -.114 & .226 & .008 & -.67 & .45 \\
\hline \multirow{5}{*}{ A9 } & \multirow[t]{2}{*}{$<=3$} & $4 \sim 7$ & $-.475^{*}$ & .157 & .012 & -.86 & -.09 \\
\hline & & $>=8$ & $-.561^{*}$ & .186 & .010 & -1.02 & -.10 \\
\hline & \multirow[t]{2}{*}{$4 \sim 7$} & $<=3$ & $.475^{*}$ & .157 & .012 & .09 & .86 \\
\hline & & $>=8$ & -.086 & .197 & .009 & -.057 & .40 \\
\hline & \multirow[t]{2}{*}{$>=8$} & $<=3$ & $.561^{*}$ & .186 & .012 & .010 & 1.02 \\
\hline \multirow{7}{*}{ B4 } & & $4 \sim 7$ & .086 & .197 & .009 & -.040 & .57 \\
\hline & \multirow[t]{2}{*}{$<=3$} & $4 \sim 7$ & -.252 & .170 & .033 & -.067 & .17 \\
\hline & & $>=8$ & -.201 & .201 & .006 & -.070 & .30 \\
\hline & \multirow[t]{2}{*}{$4 \sim 7$} & $<=3$ & .252 & .170 & .033 & -.017 & .67 \\
\hline & & $>=8$ & .051 & .213 & .009 & -.048 & .58 \\
\hline & \multirow[t]{2}{*}{$>=8$} & $<=3$ & .201 & .201 & .006 & -.030 & .70 \\
\hline & & $4 \sim 7$ & -.051 & .213 & .009 & -.058 & .48 \\
\hline
\end{tabular}

*. The significance level of average difference is 0.05 。

\section{The relativity analysis for technology level}

The technology level variable is a categorical variable and the dependent variable is a continuous variable. We started an analysis of variance of significance of the SPSS but found no significant correlation between technology level and stress factors while their significance probability $\mathrm{P}$ were higher than 0.05 . There is no scientific vale to give significant differences discussion. 
Table 15 Analysis of variance of significance --- technology level

\begin{tabular}{llcc}
\hline \multicolumn{1}{c}{ Stress factors } & Levene statistics & Significance \\
\hline A1 $\quad$ Fear into the dark tunnel & .147 & .863 \\
A2 $\quad$ Blurred vision because of some reasons like & 1.194 & .306 \\
weather & & \\
A3 $\quad$ Worry about emergency like conflict between & 1.147 & .320 \\
passengers and train & & \\
A4 & Face train and signal malfunctions & .214 & .807 \\
A5 & Small enclosed cab & 1.298 & .276 \\
A6 & Unbearable traffic noise & .627 & .536 \\
A7 & Uncomfortable sea & .533 & .588 \\
A8 & Little rest time between breaks & .026 & .974 \\
A9 & Be ill during driving & .990 & .374 \\
B1 $\quad$ Take part in vocational training and evaluation & .173 & .841 \\
B2 & Management style of leadership & 1.229 & .296 \\
B3 $\quad$ Few development opportunity for career & 1.075 & .344 \\
B4 $\quad$ Low level of autonomy & .049 & .952 \\
\hline
\end{tabular}

\section{Discussion and Suggestion}

Our research analysis got the effects of driver's related stress factors' on the work pressure. Our study data analysis demonstrated tree areas obviously, which including work load, equipment failures and management style, that producing more pressure on drivers through the establishment of urban rail train driver workload and work stress model, although the others factors also have the same properties, didn't reach that level. Further, we draw a conclusion that different individuals have different psychological reaction to the same stress factors under the comparison based on the driver's personal characteristics correlation data analysis. Of course, the purpose of research is applied to practical job, for the benefit of humanity, as we can see the data of our research on the driver's safe driving and the safety of train operation has great realistic significance, therefore, for the drivers working under pressure, here we offer some objective constructive comments:

(1) For reducing driver's workload, operating companies may improve the train drivers work environment as far as possible under the condition of operational security and transportation capacity, develop reasonable operation planning, increase the drivers' rest time, relieve drivers' fatigue by avoiding long time driving. For example, can set the middle shift in long lines, not only to alleviate fatigue, but also to prevent the driver's distraction.

(2) To reduce the pressure caused by the equipment failures, the operating company should strengthen the technical training of driver's failure resolving and psychological affordability in emergencies, at the same time strengthen the head driver's skill of guide for operation in the OCC (Operating Control Center).

(3) To reduce the pressure from management system, the company can improve the internal communication mechanisms, organize regular driver interview communication, give the driver more individual level concern. Complimenting drivers on their hard work, and to praise for outstanding drivers in order to improve the driver's satisfaction and a sense of achievement so that 
can relieve the occupational stress.

In addition, research on urban rail transit operating company's personnel selection and the improvement of the management mechanism also has reference function. Relatively speaking, the pressure model is also applicable to other transportation fields, such as aviation, navigation, etc. Methods used for our current paper expect to be referenced and improved by other researchers.

\section{Acknowledgments}

The paper is a result of a research made possible by the support of the Graduate Student Education Innovation Plan of Shanghai for enrollments in breeding program guide the layout and construction (13sc002), and under the financial support of Graduate Student Research Innovation Project of the SUES, China.

\section{References}

[1] Dai Bao-qian, Wang Tong, Jiang Yu-kun, Ding Hui. Study on Index System of Comprehensive Safety Assessment for Subway Operation System. China Safety Science Journal (CSSJ), Volume 16,No.12,2006.

[2] Xiaohong Zhang. The subway electric bus drivers psychological analysis and countermeasures[J].The Modern Enterprise.2013(3):20-21.

[3] Hans Selye. The Stress of Life. McGraw-Hill, New York, 1956

[4] Yitzhak Fried, Arie Shirom, Simona Gilboa, Cary L. Cooper. The Mediating Effects of Job Satisfaction and Propensity to Leave on Role Stress-Job Performance Relationships:

Combining Meta-Analysis and Structural Equation Modeling [J]. International Journal of Stress Management, Volume 15, Issue 4, 2008, (11): 305-328.

[5] Yu Liu, Zhenye Wu. The Structure Analysis about Railway Locomotive Drivers' Working Pressure Influence Factors[J].China Railway Science,2010,(1):130-133.

[6] Xinli Zhang, Zhuya Yang, Jinguang Wu. Research for Railway Drivers Working Pressure and Influence Factors [J]. China Railway Science,2005(2):21-27.

[7] Minglong Wu. The Questionnaire---SPSS Statistic Analysis and Practice Operation and Application[M].Chongqing: Chongqing University Press,2010.

[8] Li Shang, Yan Li, Jian Li, etc. The Impact of Working Pressure on Different Gender Career People Physical and Mental Health[J].China's Public Health,2008(12):1519-1521.

[9] Fan Yang, Yangmo Li, Li Yuan. The Empirical Study of Highly Educated Employees Work Stress Coping Styles[J]. Professional Space, 2005(12):52-54.

[10] Lanmei Cai, Jianshan Lin. Internship Students Pressure Source Investigation and Analysis[J]. The Chinese Nursing Education, 2009(8):378-380.

[11] Ning Chen, Chunxia Song. Different Age Nurses Occupational Stress Level and Its Influence on Mental Health [J]. Practical Cardio-cerebral Pulmonary Vascular Disease, 2009, 17(6):449-451.

[12] Hong Li. University Teachers' Work Pressure of Gender and Age Differences[C]. //Improve the scientific quality, To Build an Innovation-oriented Country - Annual Meeting of China Science Association. 2006.

[13] Xin Rong, Zhaobin Hui, Ruowei Shen. A Railway Locomotive Drivers' Job Burnout Influence Factors Analysis[J]. Industrial Hygiene and Occupational Diseases. 2012(38):14-18. 